\title{
Navigating the swampy lowland: a framework for evaluating the effect of community mobilisation in female sex workers in Avahan, the India AIDS Initiative
}

\author{
Christine Galavotti, ${ }^{1}$ Tisha Wheeler, ${ }^{2,3}$ Anne Sebert Kuhlmann, ${ }^{4}$ Niranjan Saggurti, \\ Pradeep Narayanan, ${ }^{6}$ Usha Kiran, ${ }^{7}$ Gina Dallabetta ${ }^{3}$
}

- An additional table is published online only. To view this file please visit the journal online (http://dx.doi.org/ 10.1136/jech-2011-200465).

${ }^{1}$ CARE, Atlanta, Georgia, USA ${ }^{2}$ Futures Group, Washington, DC, USA

${ }^{3}$ Bill \& Melinda Gates Foundation, Washington, DC, USA

${ }^{4}$ Manila Consulting Group, Inc., McLean, Virginia, USA

${ }^{5}$ Population Council, New Delhi, India

${ }^{6}$ Praxis Institute for Participatory Practices, India

${ }^{7}$ Bill \& Melinda Gates

Foundation, New Delhi, India

Correspondence to

Dr Christine Galavotti, CARE,

151 Ellis Street, Atlanta, GA

30303, USA;

cgalavotti@care.org

Accepted 2 April 2012

Published Online First

3 July 2012

\section{UN OCAKA}

This paper is freely available online under the BMJ Journals unlocked scheme, see http:// jech.bmi.com/site/about/ unlocked.xhtml

\begin{abstract}
Background Few models of how community mobilisation works have been elaborated in the scientific literature, and evaluation of the impact of these programmes on HIV and other health outcomes is extremely limited. Avahan, the India AIDS Initiative, has been implementing community mobilisation as part of its prevention programming with groups of high-risk individuals across six states since 2005.

Purpose To articulate a programme theory and evaluation framework for evaluation of Avahan's approach to community mobilisation among female sex workers in four southern states in India.

Methods The authors use a goal-based evaluation approach to describe the programme goals and an underlying programme theory that specifies how the programme is expected to work. Using multilevel structural equation modelling with propensity score matching, the evaluation will compare what is observed in the data with the predicted relationships specified by the model.
\end{abstract}

Results The Avahan model of community mobilisation posits that meaningful participation in high-risk group intervention, structural intervention and organisational development activities leads to identification, collectivisation and ownership, which in turn leads to improved programme outcomes. Strong community groups and an enabling environment reinforce social norm and behaviour change outcomes and lead to sustained impact.

Discussion Specifying an explicit programme theory can aid in the evaluation of complex interventions, especially when the evaluation design is observational. In addition to articulating Avahan's community mobilisation approach in a model that can be tested, we recommend some specific measures and methods that could be used to improve evaluation efforts in the future

There is a high, hard ground where practitioners can make effective use of research-based theory and technique, and there is a swampy lowland where situations are confusing "messes" incapable of technical solution. The difficulty is that the problems of the high ground, however great their technical interest, are often relatively unimportant to clients or to the larger society, while in the swamp are the problems of greatest human concern.

Schon, DA (1983). The Reflective Practitioner, New York: Basic Books
Community mobilisation, broadly defined, has been implemented by health and development organisations across the globe. Few models of how community mobilisation works have been elaborated in the scientific literature, however, and evaluation of the impact of these programmes on HIV and other health outcomes is extremely limited. Avahan, the India AIDS Initiative, has been implementing community mobilisation as part of its prevention programming with groups of highrisk individuals across six states since $2005^{1}$ and thus provides a unique opportunity to understand and evaluate the effect of community mobilisation on HIV prevention behaviours. Because of the scale of Avahan and the complexity of the community mobilisation process (CMP) itself, however, evaluation is extremely challenging. Furthermore, although significant resources were directed towards impact evaluation of the overall initiative, understanding how the community mobilisation component of the programme contributed to prevention outcomes was not included in the original evaluation design since this component was introduced later in the life cycle of the programme. ${ }^{2}$ In this paper, we describe Avahan's approach to community mobilisation among female sex workers (FSWs) in four southern states in India and outline the programme theory and framework for an evaluation of the programme's impact on HIV prevention outcomes.

\section{BACKGROUND}

\section{Community mobilisation}

Community mobilisation has been defined and operationalised in a variety of ways and incorporates concepts from a range of traditions, including Freirean liberatory adult education, ${ }^{3}$ participatory development ${ }^{4}$ and community psychology. ${ }^{5}$ Much of the work around community mobilisation in health uses an empowerment framework with the central idea that expanding participation of communities in programme efforts leads to empowerment and greater capacity to influence, control and sustain conditions that affect their lives. Avahan describes community mobilisation as the process by which high-risk group members "...utilize their intimate knowledge of vulnerability to overcome the barriers they face and realize reduced HIV risk and greater self-reliance through their collective action." 
Community mobilisation has been employed as an intervention strategy to address a variety of health outcomes around the world, ${ }^{6-8}$ and evaluations have shown promise. Two major cluster-randomised controlled trials of facilitated participatory action cycles among community groups showed significant reductions in neonatal mortality rates in the intervention clusters compared with control clusters. ${ }^{9}{ }^{10}$ One quasi-experimental study of community support systems for birth planning, funding of emergency transportation in Bangladesh increased knowledge of obstetric danger signs substantially more in the intervention community than in the comparison or control communities. ${ }^{11}$ In Nigeria, a quasi-experimental study of a combined community mobilisation, advocacy and mass media intervention showed positive changes in knowledge, attitudes and intentions towards eliminating female genital cutting in intervention versus control communities. ${ }^{12}$ On the other hand, a quasi-experimental study of community mobilisation for schistosomiasis control in Brazil was unable to attribute differences between the intervention and comparison villages to the community mobilisation intervention (CMI). ${ }^{13}$ Of note, some studies reporting positive outcomes combined community mobilisation with other intervention activities, such as mass media campaigns ${ }^{12}$ or healthcare facility upgrades, ${ }^{11}$ making it difficult to isolate the contribution of community mobilisation on outcomes.

\section{Interventions with sex workers}

Studies of peer HIV education interventions with sex workers have reported increased HIV knowledge ${ }^{14}$ and condom use ${ }^{15}$ as well as decreased prevalence of STDs ${ }^{14}{ }^{15}$ and HIV. ${ }^{16}$ Increasingly, community mobilisation is a central tenet within comprehensive sex worker programmes, ${ }^{17}$ as in Avahan. ${ }^{2} 1819$ One of the earliest examples, the Sonagachi Project, ${ }^{20}$ used a model called 'community-led structural interventions' (CLSI). A controlled trial replicating the CLSI model in two communities of West Bengal, India, found that the intervention increased consistent condom use in the intervention community, ${ }^{21}$ as well as built social networks and addressed environmental barriers to economic vulnerability, relative to the comparison community. ${ }^{22}$ The Sonagachi Project's CLSI model was a major contributor to the Avahan approach, as it combines elements of community participation and engagement with structural interventions (SI) to create an environment that supports social norm and behavioural change.

\section{Avahan-the India AIDS Initiative}

Avahan was launched in late 2003. ${ }^{1}$ The goal was to halt the HIV epidemic in India by rapidly building a scaled HIV prevention programme for core and bridge population groups across four southern states and two north-eastern states in India (combined population of 300 million) representing over $80 \%$ of the HIV cases in India in 2002. ${ }^{2}$ Through seven lead implementing NGO partners, who subgrant to 116 local Indian NGOs, the programme had reached over 350000 FSWs and 100000 high-risk men who have sex with men and transgenders (HR-MSM/TG) with outreach services by December 2008, and over $75 \%$ of both groups were being contacted monthly by the programme. $^{23}$ A recent study published in the Lancet concluded that over $100000 \mathrm{HIV}$ infections were averted at the population level as a result of this first phase of Avahan (2003-2008). ${ }^{24}$

For core groups (FSW, HR-MSM/TG and injection drug users), Avahan supports a package of interventions including peer-led outreach and education, treatment of sexually transmitted infections (STI), referrals for HIV and tuberculosis testing and care, and distribution of free prevention commodities (condoms and needle/syringe exchange). In addition to these interventions, Avahan supports interventions to change the structural environment of core group members' lives, and organisational development (OD) activities to build capacity and encourage participation, leadership and ownership of community-based groups and networks.

\section{EVALUATION FRAMEWORK}

The challenges to evaluating Avahan's community mobilisation approach are substantial and consistent with those facing other large-scale public health programmes. ${ }^{25} 26$ In particular, Avahan was designed for scale: the explicit intent was to 'saturate coverage' of high-risk individuals in the designated high prevalence districts in India, filling gaps in areas where other government and NGO efforts were in place, and providing intervention services in areas where there were no other HIV prevention programmes operating. This was among several reasons why there were no planned control or comparison sites and no data collection in sites where Avahan was not operating, and why data collection was focused on coverage and HIV impact measures. ${ }^{2}$ With this design, it is not possible to draw strong causal attributions: we cannot 'prove' that the CMI caused the prevention outcomes.

One commonly accepted evaluation strategy when experimental or quasi-experimental designs are not possible is 'goalbased evaluation', which uses a predetermined set of programme goals and an underlying programme theory, usually outlined in a logic model, to describe how the programme is expected to work. ${ }^{27}$ If these relationships and outcomes are observed in the data, and other alternative explanations can be reasonably eliminated, this provides plausible confirmation that the programme was successful. Figure 1 depicts several scenarios that might be observed.

\section{SPECIFYING THE MODEL}

It is not unusual when there are multiple stakeholders in a programme to have varying theories about how the programme will produce the desired effects. Realistic evaluation ${ }^{25}$ suggests that the first and most important step in an evaluation is to elicit these theories and formalise a model that can be tested in various contexts. Therefore, developing the model of how we expected community mobilisation in Avahan to work was the first step in designing an evaluation of the programme.

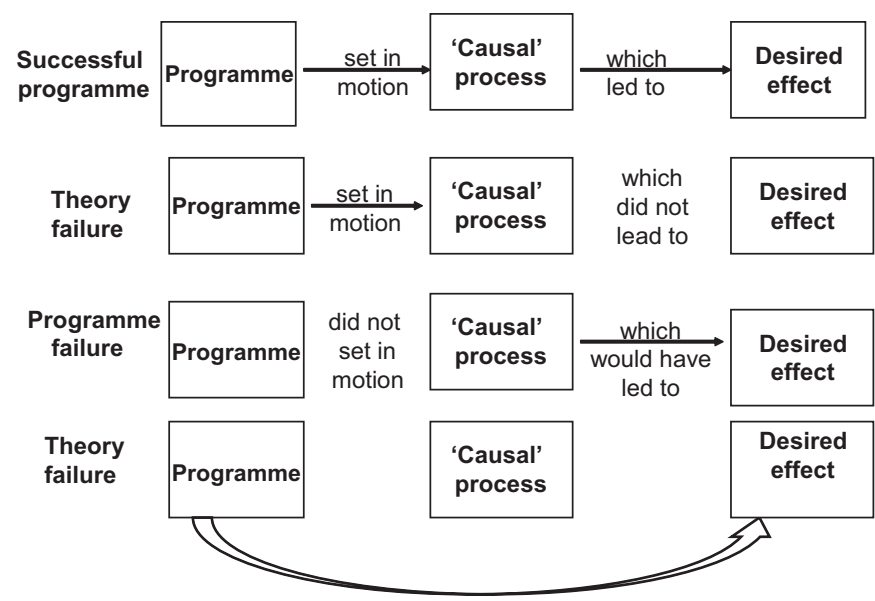

Figure 1 Understanding evaluation results using a goal-based evaluation framework. Adapted from Weiss. ${ }^{28}$ 
A basic assumption underlying the development of the model is that we are evaluating a single programme. This does not mean that the intervention was implemented uniformly or that the context was the same across Avahan. In fact, it was not. Rather, the model describes the overall conceptual underpinnings, the programme theory, behind Avahan's community mobilisation approach. This model can then be tested in multiple contexts, and with other groups of high-risk individuals, and further refined. Throughout this paper, the term 'community' is synonymous with 'groups of FSWs who come together in programme areas', and the model we propose is specific to FSWs. While certain elements of the model may be applicable to the other high-risk communities served by Avahan, we developed the model with FSW interventions in mind.

\section{COMMUNITY MOBILISATION: DEFINING THE PROGRAMME INTERVENTION AND MECHANISMS OF EFFECT}

There are two ways we refer to community mobilisation in this paper: the first corresponds to the 'programme' and the second to the 'causal processes' specified in the hypothetical model in figure 1 .

First, the programme we wish to evaluate is the CMI-this is what the programme does to actively solicit and support full and meaningful participation of the high-risk population in the intervention activities. Measures of the type and level of community participation in intervention activities are what we use to assess successful implementation and 'dose' of the CMI (described later and shown in table 1).

The second is the CMP - these are things that occur as a result of the CMI (ie, as a result of participation in the intervention activities). These are the causal processes we believe the programme sets in motion, and it is these processes that we believe lead to the desired programme outcomes.

\section{The CMI}

Avahan supports a package of intervention activities that have been roughly grouped into three categories: high-risk group interventions (HRGI) that focus on individual risk reduction (eg, condom distribution), SI that focus on vulnerability reduction (eg, crisis response teams organised to support sex workers when arrested or subjected to violence) and $\mathrm{OD}$ activities that focus on building the capacity of the community to lead and own the programme. In theory, these activities could be delivered by the implementing NGOs with little or no involvement of the community. What distinguishes the community mobilisation component of the Avahan intervention from a more standard HIV prevention intervention package is the intentional engagement of the community in these activities as actors, rather than simply as recipients of services or as paid staff. ${ }^{29} 30$ Although not implemented in a strict sequence across all Avahan districts, as the intervention unfolds, sex workers are provided support and opportunities to participate in increasingly transformational ways, ${ }^{31}$ from conducting community mapping and outreach (micro-planning), and participating in project committees, to facilitating the management of crisis response teams and taking leadership roles in formal community-based organisations.

\section{The CMP}

The goal of community participation is to mobilise the community of sex workers so that they can increasingly make decisions, influence their environment and shape their lives in ways that support their health and well-being. We characterise this process by three overlapping and mutually reinforcing stages that reflect the expanding interpersonal, social and political space that sex workers inhabit as mobilisation unfolds.

Table 1 Measures to assess the strength of the community mobilisation intervention at the cluster level*

\begin{tabular}{|c|c|}
\hline Activities & Measures of community participation $\dagger$ \\
\hline \multicolumn{2}{|l|}{ High-risk group intervention } \\
\hline Programme penetration & Number of HRls registered under project/number of HRls registered as CBO members \\
\hline \multirow[t]{3}{*}{ Programme participation } & Proportion of unpaid HRIs in cluster who participate in programme activities $\ddagger$ \\
\hline & Proportion of paid HRls in cluster who participate in programme activities \\
\hline & Categorisation of the cluster as having low, medium or high participation among unpaid and paid HRls \\
\hline \multirow[t]{3}{*}{ Micro-planning: peer-led outreach } & Ratios of unpaid and paid HRls to all participating \\
\hline & Whether any $\mathrm{HRI}$ takes the lead role in organising the micro-planning activity \\
\hline & Whether any HRI takes the lead role in analysing the micro-planning data \\
\hline \multicolumn{2}{|l|}{ Structural intervention } \\
\hline Facilitating access to entitlements & $\begin{array}{l}\text { Total number of entitlements the programme focuses on in the cluster } \\
\text { Unmet need for entitlements within the cluster }\end{array}$ \\
\hline Functional committees§ & $\begin{array}{l}\text { Proportion of paid HRI to total number of committee members from cluster who participate on committees } \\
\text { Proportion of unpaid HRI to total number of committee members from cluster who participate on committees }\end{array}$ \\
\hline Crisis response & $\begin{array}{l}\text { Proportion of paid HRls who serve as main person responding to crises to total number of those responding } \\
\text { Proportion of unpaid HRls who serve as main person responding to crises to total number of those responding }\end{array}$ \\
\hline Organised collective action & $\begin{array}{l}\text { Total number of collective events organised by cluster members } \\
\text { Ratio of paid and unpaid HRls who participate in collective action events to total number of HRls registered in cluster }\end{array}$ \\
\hline \multicolumn{2}{|l|}{ Organisational development } \\
\hline \multirow[t]{5}{*}{ Leadership and ownership by CBOs } & Existence of cluster representative on leadership team or governing body \\
\hline & $\begin{array}{l}\text { Categorisation of cluster as having low, medium, high or highest level of participation by paid and unpaid HRls in the } \\
\text { nomination process }\end{array}$ \\
\hline & Proportion of paid HRIs on the leadership team \\
\hline & Proportion of unpaid HRIs on the leadership team \\
\hline & Proportion of unpaid to paid HRls on the leadership team \\
\hline
\end{tabular}

*'Cluster' is a geographic unit at the subdistrict level that represents approximately 250 female sex workers served by the programme.

†All measures obtained from the cluster-level community participation sheet (CLCPS).

$\ddagger$ Programme activities include: outreach, advocacy, crisis response and clinic.

$\S$ Committees include: outreach, drop-in center (DIC) management, STI clinic management, crisis response, advocacy and condom.

CBO, community-based organisation; HRI, high-risk individual; STI, sexually transmitted infections. 
Stage 1: identification with others

The process of community mobilisation begins when sex workers see themselves as part of a community. ${ }^{32}$ In the early stage of the programme, Avahan provided a 'safe space' for sex workers to gather. The provision of safe space plays an important role in the process of mobilisation through the creation of both physical and social space for meeting, discourse and the development of a shared identity. ${ }^{33}$ Through identification with others, a sex worker begins to form relationships and social ties: she begins to feel "I am not alone". This is the beginning of empowerment and may affect sex workers' other relationships: an increasing sense of individual agency and self-confidence may lead to greater exercise of decision-making and power in relationships with clients and other partners. ${ }^{18}$

\section{Stage 2: collectivisation}

As social cohesion and connectedness grow, sex workers begin to see themselves not just as a loosely connected aggregate of individual sex workers but as a group that faces common concerns, experiences and needs. ${ }^{34}$ A strong sense of collective identity is vital to participants' willingness to invest emotionally in the larger entity ${ }^{32}$ and helps drive participation in mobilisation efforts. ${ }^{35}$ With support from Avahan, this is the point when sex workers begin to work together to identify issues that they can tackle as a collective and to exercise power as a group to influence other actors and processes in the wider community. If the groups' actions benefit sex workers, others in the community may see participation in the group as something worthwhile, further building a sense of collective efficacy. ${ }^{36}$ Sex workers who are either not willing, or not able, to join the group may also experience benefits as a result of the community's collective action; for example, less violence against sex workers, or more accessible services.

\section{Stage 3: ownership}

Because identification and collectivisation do not automatically lead to engagement, leadership and ownership, ${ }^{37}$ Avahan's OD activities specifically support formalisation and ownership of community groups and networks. Community-owned organisations and networks give sex workers greater power and influence: community ownership is a common factor across successful case studies of community mobilisation for HIV prevention. ${ }^{38}$ Furthermore, strong collectives support and reinforce changes in the environment that facilitate a higher quality of life for sex workers and build organisational resilience to threats such as loss of funding, police action and discrimination by health workers, leading to sustainability of programme activities and outcomes.

\section{Expected programme outputs}

The model specifies a number of programme outputs that are expected to be enhanced by the participation and mobilisation of the community, and these enhancements may in turn increase programme success. For example, greater community participation in outreach activities is expected to lead to greater coverage of the population, and more community participation in programme oversight is expected to lead to higher quality services. Other outputs include greater capacity to manage and direct programme activities, to advocate on behalf of the community and to lead community groups.

\section{Expected programme outcomes}

The primary HIV prevention behavioural outcomes established for the first 5-year phase of Avahan are consistent condom use with clients, regular STI service utilisation and increased behavioural norms for safer sex. It is hypothesised that these primary behavioural outcomes are reinforced by achievement of additional social and environmental outcomes, in particular, the presence of an enabling environment and strong community groups. As a result of all these factors, we expect longer term changes in the environment that reduce risk and vulnerability (eg, reductions in discrimination in public places, police harassment, violence against sex workers) and help sustain community organisations (eg, organisational processes that support good governance, resource mobilisation and linkages between community organisations and larger networks of sex workers).

Taken as a whole, the model depicted in figure 2 describes the following programme theory:

Meaningful participation in HRGI, SI and OD activities leads to identification, collectivisation and ownership, which are
Figure 2 Model of Avahan's programme theory for community mobilisation.

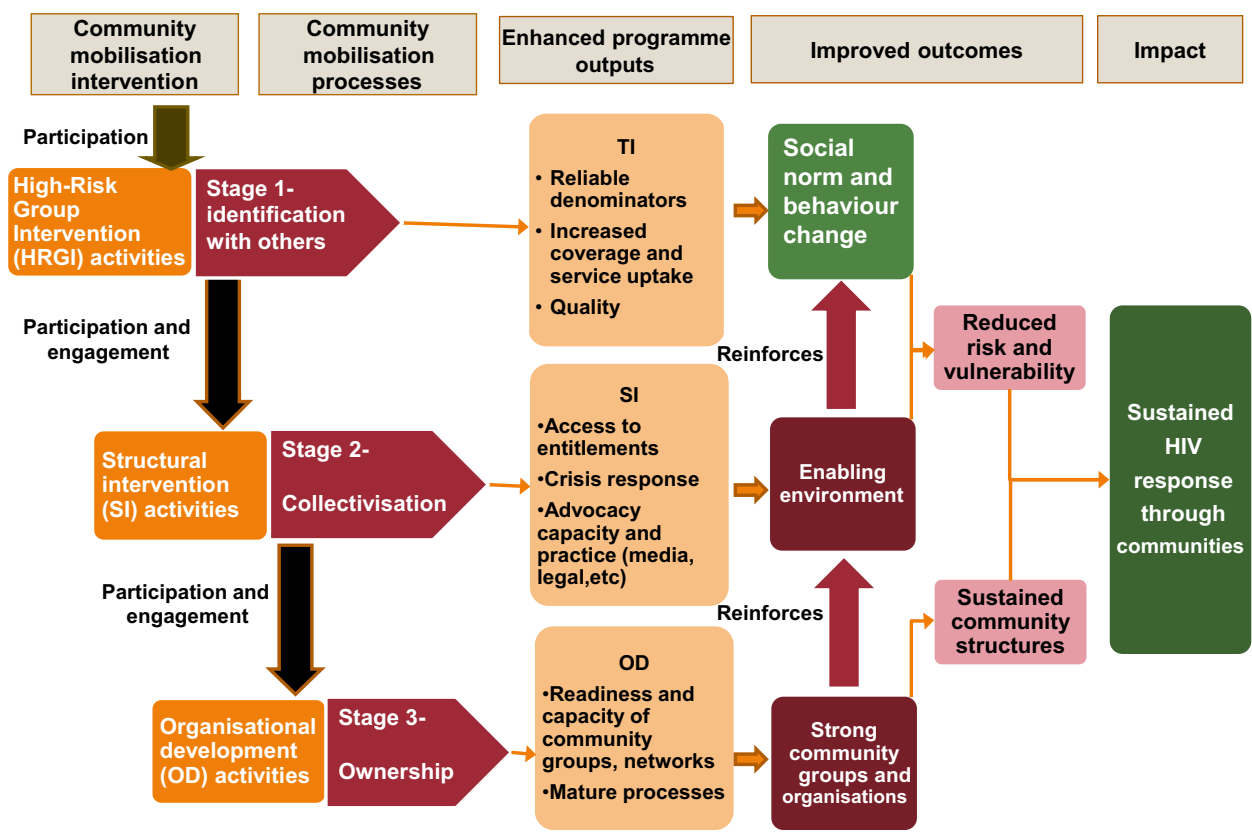


associated with increased service coverage and quality, vulnerability reduction, capacity of community groups and improved programme outcomes. Strong community groups and an enabling environment reinforce social norm and behaviour change outcomes and lead to sustained HIV prevention impact.

\section{THE PLANNED EVALUATION}

We plan to first test the programme theory model in one state, Andhra Pradesh (AP). AP was chosen for the initial evaluation in part because the two Avahan implementing partners working there (India HIV/AIDS Alliance and Hindustan Latex Family Planning Promotion Trust) were willing to conduct additional data collection. We will first evaluate the model using data from the Alliance districts, then, if the model is supported by the data, we will replicate the evaluation in the other districts. AP has the second highest estimated adult HIV prevalence rate in India and the highest among the four southern states in which Avahan works. Like the other southern states, infection is due largely to sexual contact.

This initial test of the programme theory will focus on three main components of the model: the CMI, the CMP and the primary behavioural outcomes for the first 5-year phase of Avahan. Figure 3 depicts our main hypothesis: higher levels of community participation lead to greater mobilisation (identification, collectivisation and ownership), which increases the likelihood of positive programme outcomes. This dose-response relationship via mediating factors will be analysed within a Multilevel Structural Equation Model framework. ${ }^{39}$ Due to the non-randomised nature of these observational data, we will adjust the model using propensity scores to reduce the effects of selection bias. $^{40} 41$

We limit the initial evaluation to these key components of the model for several reasons. First, a parsimonious model focused on the main question-does greater community mobilisation improve HIV prevention outcomes-is most likely to be useful to programme planners who are pressed to justify the additional time and resources associated with community mobilisation. Second, we did not include outputs in the evaluation since the type, quality and availability of the output measures varied greatly across programme components (HRGI, SI and OD) and across sites. For example, some of the output measures were collected through routine programme monitoring (eg, condoms distributed, entitlements obtained), while others were collected through extensive qualitative data collection only in selected sites (eg, capacity of community groups, organisational processes). Finally, the longer term outcomes (eg, reduced risk

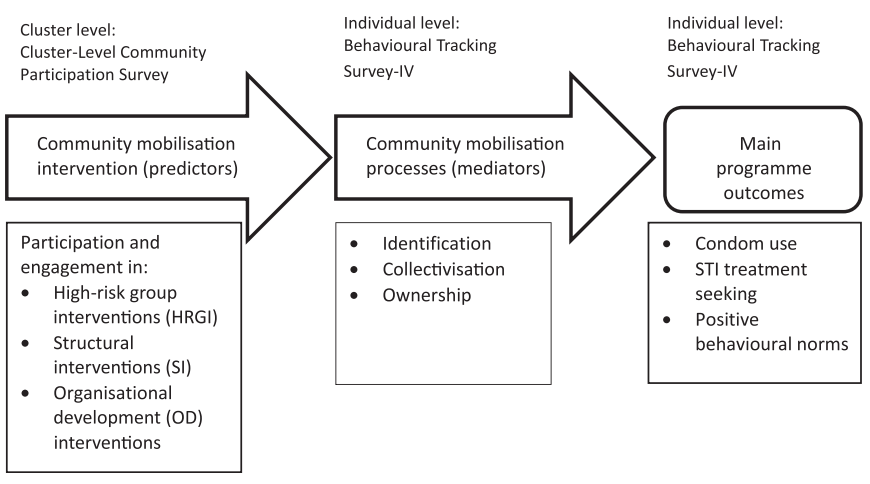

Figure 3 Relationship between the programme theory and the focus of the planned evaluation: key concepts, measures, level and source of data. STI, sexually transmitted infections. and vulnerability, sustained community structures and sustained HIV response) have yet to be fully realised and thus cannot be evaluated at this time.

We use two sources of data for this evaluation: the ClusterLevel Community Participation Survey (CLCPS) and the Behavioural Tracking Survey Version IV (BTS-IV). Both were cross-sectional assessments conducted between December 2010 and July 2011 in nine of 22 districts in AP, comprising all the districts in which the two Avahan partners work. For the initial evaluation, data from the five districts served by Alliance will be used. This will reduce variability in the intervention due to a difference in implementing partners, as well as provide an opportunity to validate the model in the other districts as a second step.

\section{Community-level measurement of strength of the intervention: the CLCPS}

Table 1 describes the measures we used to assess strength of the CMI. Although the BTS-IV included self-reported measures of exposure to, and participation in, the programme, to adequately address our main evaluation question (ie, Did a greater level of community mobilisation lead to improved programme outcomes?), it was important to have an independent measure of 'strength of the intervention'. An independent measure of intervention strength at the community level will allow us to move beyond an individual level only analysis of the effect of selfreported exposure to the intervention on outcomes. We define 'strength' as the type and level of participation of the community in the CMI, and we measured it with the CLCPS, a tool based on a much longer qualitative measure of the nature, scope and character of community mobilisation and organisation. ${ }^{42}$

The CLCPS provides a profile of community participation in the CMI at a subdistrict level, a geographic area we describe as a 'cluster'. The 'cluster area' was defined at the level of the NGO Staff Outreach Worker (ORW), who is responsible for implementation and monitoring of the programme in one or several small geographical units within each designated district of AP. The ORW supports the work of five high-risk group peer ORWs (peers) who each serve an average of 50 FSWs. In each cluster, the ORWs were interviewed using a series of questions to measure community participation in programme implementation, management, decision-making and activities including crisis response. The information provided by the ORWs was validated by structured interviews and detailed reviews of organisational documents. There were a total of 104 clusters in the five Alliance districts.

Data from the CLCPS captured the degree of autonomous community planning, implementation and oversight of programme activities and the quality of governance processes, leadership and ownership. These variables served as the basis for constructing a quantitative composite intervention exposure variable, which characterises the type and level of community participation by subdistrict cluster: we created average scores for each item in each geographic cluster, and these scores were then combined across several domains to represent the 'strength of the intervention' in that cluster. The cluster-level scores will allow us to look at the relationship between the strength of the intervention and the outcomes (eg, condom use), as well as the relationship between the strength of the intervention and the CMPs that we expect to mediate the relationship with outcomes.

\section{Individual-level measurement: the BTS-IV}

Table 2 (supplementary file) provides details on the measures of the CMP, all derived from individual-level self-reported data 
collected by the BTS-IV survey. These measures capture the process of becoming empowered, developing a sense of community and perceived solidarity, social cohesion and collective ownership.

The BTS included measures of demographics, socioeconomic situation, perceived stigma and discrimination, sex work history, condom use, perceived individual and collective agency, participation in FSW organisations and events and exposure to the local CMI programme. ${ }^{18}$ For the BTS-IV, we added time since first exposed to the CMI programme, self-efficacy scales for condom use and for service utilisation, contraceptive use, a social cohesion scale (validated for use with sex workers) ${ }^{43}$ and a mental health (depression) measure. ${ }^{44}$

The primary outcome measures to be used for this evaluation are also derived from the BTS-IV and include self-reported condom use with clients (regular and one-time), STI service utilisation and increased behavioural norms for safer sex. Behavioural norms are measured by frequency of turning away clients when they refuse to use condoms, whether any clients in past 7 days did not use a condom, and the proportion of new entrants to sex work ( $<1$ year) who report consistent condom use or refusing sex because of a client not having, or refusing to use, a condom.

From the same set of subdistrict clusters defined for the CLCPS, we randomly sampled individual FSWs for the BTS-IV using a two-stage sampling procedure. In the first stage, a fixed number of hot spots within each cluster were selected using the probability proportional to size procedure. ${ }^{45}$ In the second stage, we selected participants using either systematic sampling from non-public places (eg, brothels) or time-location cluster sampling from public places (eg, streets, parks, highways). A total of 1986 FSWs participated in the survey in the five Alliance districts.

This unique approach to measuring the strength of the intervention by subdistrict cluster, in conjunction with an independent survey of sex workers in the cluster, will allow us to explore the relationship between the strength of the CMI in the cluster and the individual-level measures of the CMPs and outcomes captured in the BTS-IV.

\section{CHALLENGES FOR EVALUATION}

Avahan awarded grants to seven state lead partners, who then provided subgrants, management and technical support to local NGOs. ${ }^{1}$ This resulted in dozens of local NGOs implementing the programme. NGOs varied with respect to skills, experience and length of engagement with the high-risk communities; some were more comfortable than others with the community leading and taking ownership of the programme. This variation, in part, will be reflected in our measure of strength of the CMI and thus will enable us to explore different 'doses' of the intervention. Other factors that may have affected programme implementation are not measured, however.

There is also significant geographic and demographic variation across Avahan, as well as variation in other features of the environment that could have influenced how the programme was implemented as well as the likelihood of programme success. These threats to validity of the findings are somewhat mitigated in this initial evaluation since we have confined it to one state. To the extent possible, contextual variables will be explicitly modelled or controlled for in analyses, including variables such as frequency of travel for sex work, location of sex work, debt, other sources of income, density of sex workers and duration of the intervention in the cluster.
Despite the many challenges with this evaluation, a complex theory-based meditational model, such as the one we propose, tends to reduce the likelihood of chance results compared with simpler models since the researcher makes a riskier 'prediction' about the specific relationships. Finally, because this is essentially an observational study, self-selection bias poses a major threat to drawing valid inferences. We use propensity score analysis to address this threat, as this method has been shown to remove about $90 \%$ of the bias resulting from non-randomised selection. ${ }^{40}$

\section{DISCUSSION}

The planned evaluation is an attempt to articulate some of the key features of a large-scale investment in community mobilisation, and how it may work to expand FSWs ability to overcome barriers they face and realise reduced HIV risk. We do so understanding that our methods are limited as much by the complex nature of the programme and the mobilisation processes themselves as by the design and the data available. Our model is a greatly simplified rendering of that complex system and set of relationships; we have tried to capture the key principles at work in that system and elucidate a few critical connections between events and outcomes, so that, if confirmed, it might serve a practical purpose. A more nuanced understanding of community mobilisation and how specific contexts facilitate or constrain programme implementation and CMP will require approaches and methods beyond what is proposed for this evaluation.

We hope by articulating a model of community mobilisation and developing measures that build on both previous research

\section{What is already known on this subject}

- Community mobilisation has been used as an intervention strategy to address a variety of health outcomes around the world.

- Few models of community mobilisation have been elaborated in the literature, and evaluation of the impact of community mobilisation on health outcomes is extremely limited.

- Community mobilisation may take many years and can be difficult and resource intensive, and thus, understanding what the most critical components of community mobilisation are and evaluating community mobilisation's relative contribution to programme outcomes are important to many stakeholders.

\section{What this study adds}

We describe Avahan's approach to community mobilisation among FSWs in India.

- We articulate a programme theory that elaborates on how participation in the intervention is expected to lead to community mobilisation and ultimately to improved programme outcomes.

- We further outline an evaluation framework for the evaluation of this large-scale CMI and describe the methods and measures that will be used to assess outcomes.

- Finally, we note the challenges associated with evaluation of complex, dynamic community interventions. 
and programme experience, we offer some guidance for others. At a minimum, we strongly recommend that programmes document community participation in the programme (level, scope and nature) from the beginning and aggregate that data at a meaningful level to assess strength of the intervention in the community over time. Baseline and follow-up surveys of intended programme beneficiaries collected in those same areas using a multistage sampling approach would then provide a stronger evaluation of how, and if, the CMI works to improve programme results. While cluster-randomised controlled trials of CMIs may be feasible and appropriate in some instances, CMIs are by their very nature complex, dynamic evolving systems that disrupt and reshape individual, social and institutional relationships in the settings in which they are introduced, and thus, we believe that more innovative methods of evaluation are needed. To generate evidence that will support the development and sustainability of better programmes, we may need to leave the hard high ground of the experimental paradigm and learn to navigate the swampy lowland.

Acknowledgements The authors gratefully acknowledge the support and helpful insights of Avahan staff including Alkesh Wadhwani, Aparajita Ramakrishnan and Ashok Alexander, and the Avahan Technical Panel including David Allen, Sundar Sundararaman, Rob Moodie, David Wilson, Marie Laga and Swarup Sakar.

Contributors CG, TW, ASK, UK and GD contributed to the articulation of the model of community mobilisation. TW, UK and GD were responsible for overseeing development and implementation of the community mobilisation intervention in India for the BMGF. CG, ASK, TW, NS and PN contributed to development of the measures of key constructs, and NS and PN oversaw data collection. CG and ASK wrote the paper with significant contributions from TW and GD. CG takes full responsibility for this manuscript.

Funding This study was funded by the Bill \& Melinda Gates Foundation. ASK's time was supported by Manila Consulting Group under contract \#200-2009-32280 with the US Centers for Disease Control and Prevention. The views expressed herein are those of the authors and do not necessarily reflect the official policy or position of the Bill \& Melinda Gates Foundation or of the Centers for Disease Control and Prevention.

Competing interests None.

Provenance and peer review Commissioned; externally peer reviewed.

\section{REFERENCES}

1. Avahan. Avahan-The India AIDS Initiative: The Business of HIV Prevention at Scale. New Delhi, India: Bill \& Melinda Gates Foundation, 2008

2. Chandrasekaran $\mathbf{P}$, Dallabetta G, Loo V, et al. Evaluation design for large-scale HIV prevention programmes: the case of Avahan, the India AIDS initiative. AIDS 2008;22 (Suppl 5):S1-15.

3. Friere P. Pedagogy of the Oppressed. New York: The Seabury Press, 1970.

4. Cornwall A, ed. The Participation Reader. UK: Zed Books, 2011.

5. Wallerstein $\mathbf{N}$, Bernstein N. Introduction to community empowerment, participatory education and health. Health Educ 0 1994;21:141-8.

6. Ahluwalia IB, Schmid T, Kouletio M, et al. An evaluation of a community-based approach to safe motherhood in northwestern Tanzania. Int J Gynaecol Obstet 2003;82:231-40.

7. Kerrigan D, Telles $\mathrm{P}$, Torres $\mathrm{H}$, et al. Community development and HIV/STI-related vulnerability among female sex workers in Rio de Janeiro, Brazil. Health Educ Res 2008;23:137-45

8. Dongre AR, Deshmukh PR, Garg BS. A community based approach to improve health care seeking for newborn danger signs in rural Wardha, India. Indian J Pediatr 2009;76:45-50.

9. Manandhar DS, Osrin D, Shrestha BP, et al. Effect of a participatory intervention with women's groups on birth outcomes in Nepal: cluster-randomised controlled trial. Lancet 2004;364:970-9.

10. Tripathy $\mathbf{P}$, Nair N, Barnett $\mathrm{S}$, et al. Effect of a participatory intervention with women's groups on birth outcomes ad maternal depression in Jharkhand and Orissa, India. Lancet 2010;375:1182-92.

11. Hossain J, Ross SR. The effect of addressing demand for as well as supply of emergency obstetric care in Dinajpur, Bangladesh. Int J Gynaecol Obstet 2006;92:320-8

12. Babalola S, Brasington A, Agbasimalo A, et al. Impact of a communication programme on female genital cutting in eastern Nigeria. Trop Med Int Health 2006;11:1594-603.

13. Uchoa E, Barreto SM, Firmo JOA et al. The control of schistosomiasis in Brazil: an ethno-epidemiological study of the effectiveness of a community mobilization program for health education. Soc Sci Med 2000:51:1529-41.
14. Ford K, Wirawan DN, Reed BD, et al. The Bali STD/AIDS study: evaluation of an intervention for sex workers. Sex Transm Dis 2002;29:50-8.

15. Rou K, Wu Z, Sullivan SG, et al. A five-city trail of a behavioural intervention to reduce sexually transmitted disease/HIV risk among sex workers in China. AIDS 2007;21:S95-101.

16. Ghys PD, Diallo M0, Ettienge-Traore V, et al. Effect of intervention to control sexually transmitted disease on the incidence of HIV infection in female sex workers. AIDS 2001;15:1421-31.

17. Shahmanesh M, Patel V, Mabey D, et al. Effectiveness of interventions for the prevention of HIV and other sexually transmitted infections in female sex workers in resource poor settings: a systematic review. Trop Med Int Health 2008; 13:1-21.

18. Blankenship KM, West B, Kershaw T, et al. Power, community mobilization, and condom use practices among female sex workers in Andhra Pradesh, India. AIDS 2008:22:S109-16.

19. Reza-Paul S, Beattie T, Syed HUR, et al. Declines in risk behaviour and sexually transmitted infection prevalence following a community-led HIV preventive intervention among female sex workers in Mysore, India. AIDS 2008;22 S $91-100$.

20. Jana S, Bandvopahvay N, Mukherjee S, et al. STD/HIV intervention with sex workers in West Bengal, India. AIDS 1998;12:S101-8

21. Basu I, Jana S, Rotheram-Borus MJ, et al. HIV prevention interventions among sex workers in India. J Acquir Immune Defic Syndr 2004;36:845-52.

22. Swendeman D, Basu I, Das $S$, et al. Empowering sex workers in India to reduce vulnerability with HIV and sexually transmitted diseases. Soc Sci Med 2009:69:1157-66.

23. Verma R, Shekar A, Khobragade S, et al. Scale-up and coverage of Avahan: a large scale HIV-prevention programme among female sex workers and men who have sex with men in four Indian states. Sex Transm Infect 2010;86 i76-82.

24. $\mathbf{N g ~ M}$, Gakidou E, Levin-Rector A, et al. Assessment of population-level effect of Avahan, an HIV-prevention initiative in India. Lancet 2011;378:1643-52.

25. Pawson R, Tilley N. Realistic Evaluation. London: Sage Publications, 1997.

26. Victora CG, Black RE, Boerma JT, et al. Evidence-based public health: moving beyond randomized trials. Am J Public Health 2004;94:400-5.

27. Centers for Disease Control and Prevention. Introduction to Program Evaluation in Public Health Programs: A Self-Study Guide. Atlanta: Centers for Disease Control and Prevention, 2005

28. Weiss CH. Evaluation Research. Englewood Cliffs, NJ: Prentice Hall, 1972.

29. Wheeler T, Kiran U, Dallabetta G, et al. Learning about scale, measurement and community mobilization: reflections on the implementation of the Avahan HIV/AIDS Initiative in India. J Epidemiol Community Health 2012:66:ii16-ii25.

30. Biradavolu MR, Blankenship KM, Jena A, et al. Structural stigma, sex work, and HIV: contradictions and lessons learnt from a community-led structural intervention in southern India. J Epidemiol Community Health 2012;66:ii95-ii9.

31. White S. The uses and abuses of participation. In: Pearce J, ed. Development, NGOs, and Civil Society. United Kingdom: Oxfam, 2000:142-55.

32. Gamson WA. The social psychology of collective action. In: Morris AD, Mueller CM eds. Frontiers in Social Movement Theory. New Haven: Yale University Press, 1992:53-76.

33. deSouza R. Creating "communicative spaces": a case of NGO community organizing for HIV/AIDS prevention. Health Commun 2009;24:692-702.

34. Taylor V, Whittier NE. Collective identity in social movement communities: lesbian feminist mobilization. In: Morris AD, Mueller CM, eds. Frontiers of Social Movement Theory. New Haven: Yale University Press, 1992:104-28.

35. Polletta F, Jasper JM. Collective identity and social movements. Annu Rev Sociol 2001;27:283-305.

36. Lee FLF. Collective efficacy, support for democratization, and political participation in Hong Kong. Int J Public Opin Res 2006;18:297-317.

37. Cornish F, Ghosh R. The necessary contradictions of 'community-led' health promotion: a case study of HIV prevention in an India red light district. Soc Sci Med 2007;64:496-507.

38. Garmaise D, de Bruyn T. Stories of Community Mobilization. s.I.: Canadian HIVIAIDS Legal Network. 2004. http://edocs.lib.sfu.ca/projects/chodarr/documents/ chodarr0861.pdf

39. Bryan A, Schmiege SK, Broaddus MR. Mediational analysis in HIV/AIDS research: estimating multivariate path analytic models in a structural equation modeling framework. AIDS Behav 2007;11:365-83.

40. D'Agostino RB. Propensity score methods for bias reduction in the comparison of a treatment to a non-randomized control group. Stat Med 1998;17:2265-81.

41. Hoshino T, Kurata H, Shigemasu K. A propensity score adjustment for multiple group structural equation modeling. Psychometrika 2006:71:691-712.

42. Thomas T, Narayanan P, Wheeler $T$, et al. Design of a community ownership and preparedness index: using data to inform community capacity development. J Epidemiol Community Health 2012;66:ii26-ii33.

43. Lippman SA, Donini A, Diaz J, et al. Social-environmental factors and protective sexual behavior among sex workers: the Encontros intervention in Brazil. Am J Public Health 2009:99:S216-23.

44. Kroenke K, Spitzer RL, Williams JB, et al. The patient health questionnaire-2: validity of a two-item depression screener. Med Care 2003:41:1284-92.

45. Levy PS, Lemeshow S. Sampling of Populations: Methods and Applications. 3rd edn New York: Wiley, 1999 